\title{
Dose-response relation of self-reported and accelerometer-measured physical activity to perceived health in middle age - the Northern Finland Birth Cohort 1966 Study
}

Maisa S. Niemelä ${ }^{1,2,3^{*}}$ (D), Maarit Kangas ${ }^{1,3}$, Riikka J. Ahola ${ }^{4}$, Juha P. Auvinen ${ }^{3,5}$, Anna-Maiju Leinonen ${ }^{1,2,6}$, Tuija H. Tammelin ${ }^{7}$, Eeva S. Vaaramo ${ }^{5}$, Sirkka M. Keinänen-Kiukaanniemi ${ }^{3,5,8,9}$, Raija I. Korpelainen ${ }^{3,5,6}$ and Timo J. Jämsä 1,2,3,10

\begin{abstract}
Background: Regular physical activity (PA) promotes health and decreases mortality. The positive relationship between PA and perceived health $(\mathrm{PH})$ is well known. However, previous research in the field has often used self-reported PA measures. The aim of this population-based NFBC1966 birth cohort study was to assess the relationship between both self-reported and objectively measured PA and PH in midlife.

Methods: A sample group of 6384 participants (2878 men, 3506 women, response rate 62\%) aged 46 completed a questionnaire on PH and health behaviors, including items on weekly leisure time physical activity (LTPA) and daily sitting time (ST). PH was dichotomized as good (very good or good) and other (fair, poor, or very poor). PA was measured with a wrist-worn Polar Active (Polar Electro, Finland) accelerometer for 14 days $(n=5481,98 \%)$ and expressed as daily average time spent in moderate to vigorous intensity PA (MVPA). Odds ratios (OR) and 95\% confidence intervals for good $\mathrm{PH}$ were calculated using binary logistic regression and adjusted for relevant demographic, socioeconomic, and health characteristics, and ST.

Results: The level of PA was positively associated with PH after adjustments with covariates and ST. There was a dose-response relationship across the PA quartiles according to the adjusted multivariable models. Self-reported LTPA was more strongly associated with good PH (OR from 1.72 to 4.33 compared to lowest PA quartile) than objectively measured PA (OR from 1.37 to 1.66 compared to lowest PA quartile).
\end{abstract}

Conclusions: In this large population-based birth cohort study, we for the first time show a positive doseresponse relationship of both self-reported and objectively measured PA to $\mathrm{PH}$, the relationship being stronger for self-reported LTPA. Despite the cross-sectional design of this study, the results from this large sample suggest that both self-reported and objectively measured physical activity are strongly associated with $\mathrm{PH}$, which is a predictor of morbidity and mortality, and regular PA should be encouraged in midlife.

Keywords: Physical exercise, Questionnaires, Self-rated health, Middle aged

\footnotetext{
* Correspondence: maisa.niemela@oulu.fi

${ }^{1}$ Research Unit of Medical Imaging, Physics and Technology, University of Oulu, PO Box 5000, 90014 Oulu, Finland

${ }^{2}$ Infotech, University of Oulu, Oulu, Finland

Full list of author information is available at the end of the article
}

(c) The Author(s). 2019 Open Access This article is distributed under the terms of the Creative Commons Attribution 4.0 International License (http://creativecommons.org/licenses/by/4.0/), which permits unrestricted use, distribution, and reproduction in any medium, provided you give appropriate credit to the original author(s) and the source, provide a link to the Creative Commons license, and indicate if changes were made. The Creative Commons Public Domain Dedication waiver (http://creativecommons.org/publicdomain/zero/1.0/) applies to the data made available in this article, unless otherwise stated. 


\section{Background}

Perceived health ( $\mathrm{PH}$; also known as self-rated health and self-perceived health) is a widely used, inexpensive health measure. Most often a single-item question asking individuals to rate their current health status on a 4- or 5-point scale from poor to excellent is used. $\mathrm{PH}$ is a subjective health measure that includes physical, mental, emotional, and functional aspects of health [1]. PH has been shown to be associated with mortality, morbidity, and objective health status [2,3] and to predict mortality after controlling for objective health status [2]. In some cases, it has been an even stronger predictor of survival than medical records [4].

Lifestyle, social, and work-related factors have been identified as determinants of $\mathrm{PH}[3,5,6]$, and it has been acknowledged that people with similar health conditions may provide different answers to a $\mathrm{PH}$ question [7]. Thus, PH includes components beyond objective health status, as Maddox and Douglass noted decades ago: "These ratings clearly measure something moreand something less - than objective medical rating" [8].

It has been widely established that sufficient and regular physical activity (PA) enhances health and decreases the risk of morbidity and mortality. The lack of physical activity, or physical inactivity, increases the risk of many non-communicable diseases and shortens the lifespan over three years $[9,10]$, and the global cost of physical inactivity was evaluated as more than 53 billion international dollars in 2013 [11].

Recently, objective wearable measuring devices such as accelerometers and pedometers have become popular in the PA research field [12]. They provide accurate information about PA due to the lack of common errors (recall, and social desirability bias) inherent in self-reports of PA [13]. However, both measuring conditions may cause reactivity, i.e. changes in habitual PA behavior during the measurement period.

Self-reported leisure-time PA (LTPA) [14, 15] and moderate to vigorous PA (MVPA) measured with an accelerometer [16-18] have both separately been reported to be associated with $\mathrm{PH}$ in many age groups. However, previous research on the determinants of $\mathrm{PH}$ has often relied on self-reported $\mathrm{PA}$, and questions have been raised about the potential conceptual overlap between self-reported PA and health due to the complex nature of human perception of health and well-being, including physical, social, and mental constructs [16]. To our knowledge, few studies have compared objective and subjective PA measures in relation to subjective health measures. Anokye et al. reported a stronger relationship between objective PA and health-related quality of life (HRQoL) compared to subjectively measured PA [19].

Sedentary time increases in adulthood with age, and those participating in LTPA or occupational PA in early middle age are more likely to engage in LTPA as they age $[20,21]$. Additionally, a connection between higher age and poorer $\mathrm{PH}$ has been recognized [22]. Therefore, reaching a sufficient level of $\mathrm{PA}$ in middle age, and maintaining this level while aging, is a key factor for healthy aging. Thus, the aim of the study was to determine and compare the relationship between self-reported and accelerometer-measured PA and $\mathrm{PH}$ in midlife, in the context of a wide population-based birth cohort study from Northern Finland. To our knowledge, this is the first study exploring the relationship between both measured and self-reported $\mathrm{PA}$ and $\mathrm{PH}$ in a single study setup. We hypothesized that both PA variables have a positive association with $\mathrm{PH}$ and that objectively measured PA might have a stronger association compared to self-reported PA due to its ubiquitous nature including all measured activities around the clock.

\section{Methods \\ Study population}

The Northern Finland Birth Cohort 1966 study (NFBC 1966) includes subjects in Northern Finland whose dates of birth fell in the year $1966(n=12,058$ live births) [23]. Information about these individuals has been recorded regularly since their birth through health care records, questionnaires, and clinical examinations, and data has been collected on their parents and offspring. The study was approved by the Ethical Committee of the Northern Ostrobothnia Hospital District in Oulu, Finland (94/2011), and it has been performed in accordance with the Declaration of Helsinki. The subjects and their parents provided written consent for the study. Personal identity information was encrypted and replaced with identification codes to provide full anonymity. This study analyzed the data obtained from the most recent time point, at which time participants were 46 years old $(n=10,321)$. Participants attended clinical examinations $(n=5852)$, where trained nurses thoroughly assessed their medical condition, their height and weight were measured, and their BMI (body mass index) calculated.

\section{Questionnaire}

Postal questionnaires were sent to all participants with known addresses in 2012-2014 (PA questionnaire response rate $62 \%, n=6384)$. Questionnaires included items about participants' health, behavior, and social background. Their marital status, education, employment status, annual household income, and prevalence of diagnosed diseases were addressed. Smoking status (former, current, non-smoker) and alcohol consumption (g/day) were composed based on multiple questions about drinking and smoking habits. 
Participants were asked about their $\mathrm{PH}$ with the question "How would you describe your health at the moment?" The response alternatives were 1) very good, 2) good, 3) fair, 4) poor, and 5) very poor. The PH responses were dichotomized as good (very good and good) and other (fair, poor, and very poor) [2].

LTPA was self-reported with questions on the frequency and duration of light and brisk physical activities or exercises during leisure time, as was done in the 31years follow-up study (24). Brisk PA was described as causing at least some sweating and breathlessness, while light PA was defined as causing no sweating or breathlessness. PA frequency had six response options: 1) once a month or less often, 2) 2-3 times a month, 3) once a week, 4) 2-3 times a week, 5) 4-6 times a week, and 6) daily. PA duration had the following response options: 1 ) not at all, 2) less than $20 \mathrm{~min}, 3) 20-39 \mathrm{~min}, 4)$ 40-59 min 5) $1-1.5 \mathrm{~h}$, and 6) more than $1.5 \mathrm{~h}$ [24]. Weekly averages of metabolic equivalent of a task (MET) minutes of light and brisk PA were calculated by multiplying the PA volume (duration*frequency) by its intensity (light PA 3 METs and brisk PA 5 METs) [25].

Daily sitting time (ST) was assessed with the question "How much time do you spend sitting on a normal weekday?" The response was divided to describe the amount of sitting in five domains (at work, at home watching TV or video, at home in front of computer, in a vehicle, and in another place) [26]. Average daily ST (min/day) was calculated as a sum of durations of these sedentary behaviors. Those reporting ST higher than $18 \mathrm{~h} /$ day $(n=27)$ were excluded from analyses concerning ST.

\section{Accelerometer-measured physical activity}

PA was objectively measured with wrist-worn activity monitors (Polar Electro Oy, Kempele, Finland) for 14 days. Polar Active is a waterproof accelerometer providing MET values every $30 \mathrm{~s}$ based on daily PA [27]. Polar Active has been shown to correlate $\left(R^{2}=0.74\right)$ with the double-labelled water technique when measuring energy expenditure during exercise [28]. It uses height, weight, gender, and age of the user as predefined inputs. Each activity monitor was blinded, giving no feedback to the user, and the monitors were given to the participants during clinical examinations, with participants being instructed to mail them back after the measurement period. Participants were asked to wear the Polar Active monitor $24 \mathrm{~h}$ /day for at least 14 days on the non-dominant hand. Measured PA was classified as five levels (very light: 1-2 MET, light: 2-3.5 MET, moderate: 3.5-5 MET, vigorous: 5-8 MET, and vigorous $+\geq 8$ MET) [29]. Daily averages of duration spent in activity levels (min/day) were calculated for all participants. All activity performed with the intensity of 3.5
MET or higher was assessed as MVPA (min/day), and MVPA MET-minutes were calculated by multiplying each MET value with its duration (30s). The first day when the activity monitor was given to the participant was excluded from the analysis. Participants with four or more eligible days (wear time of at least $600 \mathrm{~min} /$ day) were included in the analyses (Fig. 1) [30].

\section{Statistics}

The descriptive data is presented as numbers and percentages, means, standard deviations (SD) or medians, and 25th and 75th percentiles for skewed data. Accelerometermeasured moderate, vigorous, and very vigorous intensity PA and MVPA were natural log-transformed to obtain normal distribution. Non-transformed values are presented in the tables. Univariate associations between continuous variables and gender and $\mathrm{PH}$ were analyzed using the independent-samples t-test, with Tukey post hoc tests for normally distributed variables and with the independent-samples Mann-Whitney U test for skewed data. The agreement between objectively measured MVPA and questionnaire based LTPA as MET-minutes was evaluated with Spearman's rank correlation coefficient (r). The associations of demographic, socioeconomic, and health characteristics to $\mathrm{PH}$ were studied

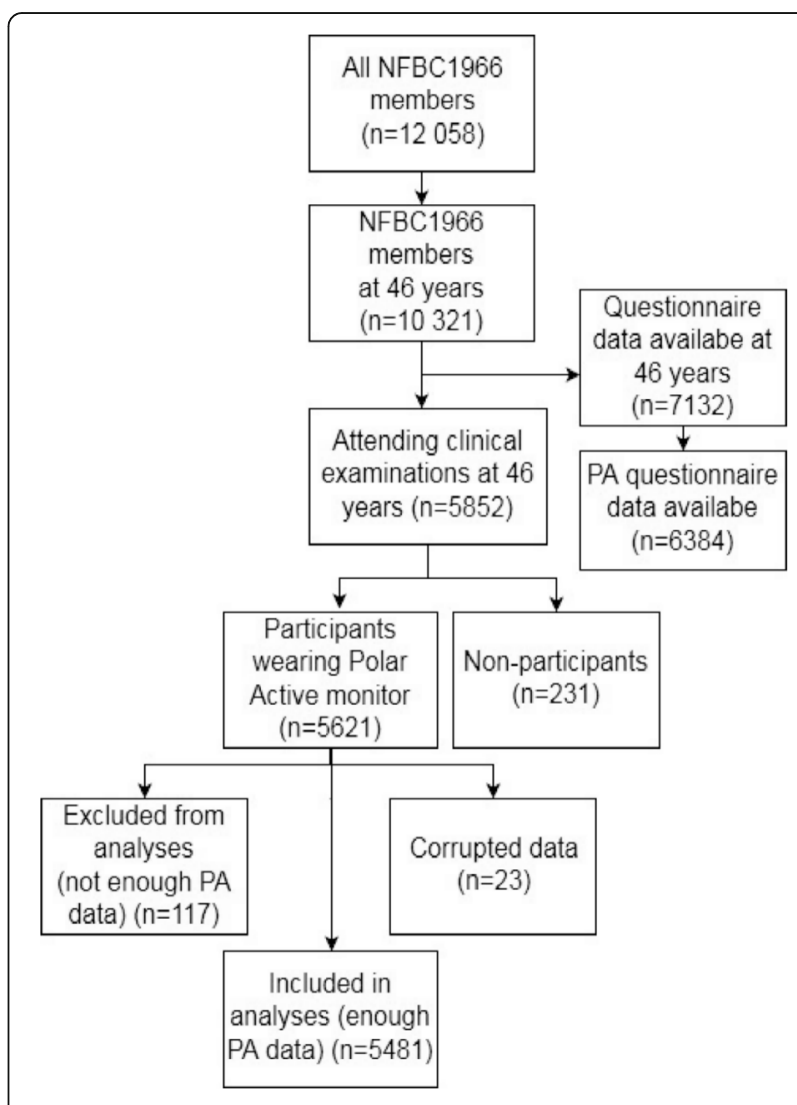

Fig. 1 Northern Finland Birth Cohort 1966 (NFBC1966) participants 
through binary logistic regression analysis. $\mathrm{PH}$ was controlled for gender, marital status (married/cohabiting, unmarried), employment status (working, unemployed, other), education (vocational or no vocational education, polytechnic/university degree), prevalence of diagnosed diseases (cardiovascular disease, diabetes mellitus, cancer, musculoskeletal diseases, or mental disorder), smoking (former, current, non-smoker), heavy alcohol consumption (men $\geq 40 \mathrm{~g} /$ day, women $\geq 20$ g/day), BMI (body mass index $\mathrm{kg} / \mathrm{m}^{2}$, as continuous variable), income (quartiles of yearly household income), and ST (min/day, quartiles). Model 1 included in addition accelerometer-measured MVPA (min/week, quartiles), while Model 2 included self-reported LTPA (min/week, quartiles) instead of MVPA. Odds ratios (OR) and 95\% confidence intervals (95\% CI) for good $\mathrm{PH}$ were calculated, and ORs were adjusted for all the variables. The significance of the models was evaluated using the likelihood ratio test $\left(\chi^{2}\right)$ and Nagelkerke $R^{2}$ value. Statistical significance was set to $p<0.05$, and statistical analyses were performed with IBM SPSS Statistics for Windows, version 24.0 (IBM Corp., Armonk, USA).

\section{Results}

The study population consisted of 3291 (46\%) men and 3841 (54\%) women (Table 1).

The PA questionnaire was completed by 6384 participants, and ST questions were answered by 6735 participants. Self-reported LTPA and corresponding MET-minutes and self-reported STs are presented in Table 2. The weekly median of self-reported LTPA (total activity) was $225 \mathrm{~min} / \mathrm{wk}$., which corresponds to a total amount of 788 MET-min/wk. Women reported significantly more PA than men $(p<0.001)$. Self-reported overall median ST was 450 (300-600) min/day. Men reported 60 min more sitting per day than women $(\mathrm{p}<0.05)$. Most of the time spent sitting took place at work and at home watching TV or video (Table 2).

PA was measured by accelerometer, with 5621 participants from which eligible activity data was available from 5481 (98\%). In addition, for some participants, the data had been corrupted and could not be restored due to activity monitors malfunctioning $(n=23)$. Those who provided eligible activity data were more often employed $(p=0.02)$ than the participants who did not have enough PA data (data not shown). For those with eligible PA data, the average measurement period was 13 days and average wearing time during waking hours was 978 (62) min/day. The weekly average of accelerometer-measured MVPA was $483 \mathrm{~min} / \mathrm{wk}$. (2590 MET-min/wk). Men had on average more MVPA and very light activity and less light activity compared to women $(p<0.001)$. The correlation between accelerometer-measured MVPA and
Table 1 Characteristics of the study population $(n=7132)$

\begin{tabular}{|c|c|c|c|}
\hline Variable & $\begin{array}{l}\text { Men } \\
(n=3291)\end{array}$ & $\begin{array}{l}\text { Women } \\
(n=3841)\end{array}$ & $\begin{array}{l}\text { All } \\
(n=7132)\end{array}$ \\
\hline Height, cm & $178.5(6.3)$ & $164.8(6.0)$ & $170.8(9.1)$ \\
\hline Weight, kg & $87.2(14.9)$ & $72.0(14.9)$ & $78.7(16.7)$ \\
\hline BMI, body mass index & $27.3(4.3)$ & $26.5(5.3)$ & $26.9(4.9)$ \\
\hline \multicolumn{4}{|l|}{ Education } \\
\hline No professional education & $148(5 \%)$ & $106(3 \%)$ & $254(4 \%)$ \\
\hline $\begin{array}{l}\text { Vocational/college level } \\
\text { education }\end{array}$ & $2174(72 \%)$ & $2339(66 \%)$ & $4513(68 \%)$ \\
\hline $\begin{array}{l}\text { Polytechnic/university } \\
\text { degree }\end{array}$ & $699(23 \%)$ & 1125 (31\%) & $1824(28 \%)$ \\
\hline \multicolumn{4}{|l|}{ Employment status } \\
\hline Employed & $2571(87 \%)$ & $3051(87 \%)$ & $5622(87 \%)$ \\
\hline Studying & $33(1 \%)$ & $68(2 \%)$ & $101(2 \%)$ \\
\hline Unemployed & $220(8 \%)$ & $182(5 \%)$ & $402(6 \%)$ \\
\hline Other & $122(4 \%)$ & 207 (6\%) & $329(5 \%)$ \\
\hline \multicolumn{4}{|l|}{ Smoking } \\
\hline Non-smoker & $1366(45 \%)$ & 2086 (57\%) & 3452 (51\%) \\
\hline Current smoker & $762(25 \%)$ & $697(19 \%)$ & $1459(22 \%)$ \\
\hline Former smoker & $923(30 \%)$ & $872(24 \%)$ & $1795(27 \%)$ \\
\hline \multicolumn{4}{|l|}{ Alcohol consumption } \\
\hline $\begin{array}{l}\text { Alcohol consumption, } \\
\text { g/day }\end{array}$ & $8.5(2.4-21.8)$ & $2.9(0.6-8.1)$ & $4.7(1.0-14.0)$ \\
\hline Heavy users ${ }^{*}$ & $330(11 \%)$ & $291(8 \%)$ & $621(9 \%)$ \\
\hline
\end{tabular}

values are numbers (\%), mean (SD), or median (25th -75 th percentile), ${ }^{*}$ Heavy users men $\geq 40 \mathrm{~g} /$ day, women $\geq 20 \mathrm{~g} /$ day

self-reported LTPA MET-minutes was low $(r=0.296$, $\mathrm{p}$ $<0.001)$. The mean daily time spent on different PA levels are presented in Table 3.

Over half the study population (53\%) perceived their health as good, $13 \%$ as very good, and 30,3 , and $1 \%$ as fair, poor, and very poor, respectively. The amount of accelerometer measured MVPA and self-reported LTPA was significantly higher among those who rated their health as at least good compared to those who rated it less than good ( $\mathrm{p}<0.001$; Table 4$)$. There was no significant difference between self-reported ST in those with good PH compared to others $(p=0.25)$.

Both multivariate logistic regression models (Table 5) were statistically significant at the level of $\mathrm{p}<0.001$ in the likelihood ratio test $\left(\chi^{2}=704.35\right.$ and $X^{2}=882.19$ for Models 1 and 2, respectively). The Nagelkerke $R^{2}$ values were 0.212 and 0.262 for Models 1 and 2, respectively. MVPA (Model 1) was positively associated with good $\mathrm{PH}$ after adjustment of gender, BMI, prevalence of diseases, smoking, alcohol consumption, ST, and socioeconomic factors. MVPA ORs were greater $(\mathrm{ORs}=1.37$, 1.49 , and 1.66) for the second, third, and fourth quartiles, respectively, compared to the lowest one. Furthermore, greater LTPA (Model 2) was associated with 
Table 2 Self-reported leisure time physical activity (PA; min/wk) and sitting time (ST; min/day)

\begin{tabular}{llll}
\hline PA and ST type & Men $^{a}$ & Women & \\
\hline Total PA (min/wk) & $188(75-345)^{*}$ & $233(115-398)$ & $225(90-375)$ \\
Light PA (min/wk) & $75(30-210)^{*}$ & $113(50-225)$ & $113(45-210)$ \\
Brisk PA (min/wk) & $75(10-188)^{*}$ & $75(23-188)$ & $75(15-188)$ \\
Total PA (MET-min/wk) & $713(248-1350)^{*}$ & $855(435-1500)$ & $788(938-1463)$ \\
Total sitting time (min/d) & $480(315-615)^{* *}$ & $420(270-570)$ & $450(300-600)$ \\
Sitting at work (min/d) & $210(60-360)^{* *}$ & $210(60-390)$ & $210(60-390)$ \\
Sitting at home watching TV or video (min/d) & $120(60-150)^{* *}$ & $120(60-120)$ & $120(60-120)$ \\
Sitting at home in front of computer (min/d) & $60(30-60)^{* *}$ & $30(30-60)$ & $60(30-60)$ \\
Sitting in a vehicle (min/d) & $60(30-90)^{* *}$ & $30(15-60)$ & $40(30-60)$ \\
Sitting in an another place (min/d) & $0(0-60)^{* *}$ & $0(0-60)$ & $0(0-60)$ \\
\hline
\end{tabular}

median (25th-75th percentiles), ${ }^{a}$ for PA: men $(n=2878)$, women $(n=3506)$, all $(n=6384)$, for ST: men $(n=3681)$, women $(n=3054)$, all $(n=6735)$, ${ }^{*}$ ifferent from women $(p<0.001),{ }^{* *}$ different from women $(p<0.05)$

higher odds of good PH (ORs = 1.72, 2.41, and 4.33) for the second, third, and fourth quartiles respectively (Table 5). University or polytechnic degree, higher income (two highest quartiles), lack of diagnosed diseases, and marriage/cohabitation increased the odds of good $\mathrm{PH}$. In contrast, heavy alcohol consumption, smoking, and higher BMI were associated with lower odds of good $\mathrm{PH}$. ST and gender were not associated with $\mathrm{PH}$.

\section{Discussion}

The aim of this population-based study was to investigate and compare the relationship of self-reported and accelerometer-measured physical activity to PH in midlife. The main finding was that both self-reported LTPA and accelerometer-measured MVPA were significantly and positively associated with $\mathrm{PH}$. To our knowledge, this study for the first time reports the dose-response association between both self-reported and accelerometermeasured PA and PH in a large cross-sectional setup.

Table 3 Daily minutes of accelerometer-measured physical activity (PA)

\begin{tabular}{llll}
\hline Accelerometer measured PA & $\begin{array}{l}\text { Men } \\
(N=2413)\end{array}$ & $\begin{array}{l}\text { Women } \\
(N=3068)\end{array}$ & $\begin{array}{l}\text { All } \\
(N=5481)\end{array}$ \\
\hline $\begin{array}{l}\text { Very light intensity PA } \\
(1-2 \text { MET) (min/d) }\end{array}$ & $644(95)^{*}$ & $621(88)$ & $631(92)$ \\
$\begin{array}{l}\text { Light intensity PA } \\
(2-3.5 \text { MET) (min/d) }\end{array}$ & $266(70)^{*}$ & $288(73)$ & $278(72)$ \\
$\begin{array}{l}\text { Moderate intensity PA } \\
(3.5-5 \text { MET) (min/d) }\end{array}$ & $48(25)^{*}$ & $28(15)$ & $37(22)$ \\
$\begin{array}{l}\text { Vigorous intensity PA } \\
(5-8 \text { MET) (min/d) }\end{array}$ & $18(13)^{*}$ & $28(17)$ & $23(16)$ \\
$\begin{array}{l}\text { Very vigorous intensity PA } \\
(>8 \text { MET) (min/d) }\end{array}$ & $12(13)^{*}$ & $5(7)$ & $8(10)$ \\
$\begin{array}{l}\text { MVPA ( } \geq 3.5 \text { MET) (min/d) } \\
\text { MVPA MET-minutes (MET-min/d) }\end{array}$ & $79(39)^{*}$ & $61(234)$ & $69(35)$ \\
\hline
\end{tabular}

mean (SD), ${ }^{*}$ different from women $(p<0.001), M V P A=$ Moderate to Vigorous Physical Activity
In the present study, the amount of accelerometer measured MVPA and self-reported LTPA was higher among those who perceived their health as at least good compared to those with fair, poor, or very poor health. When adjusted for socioeconomic, demographic, and health factors and ST, both MVPA and LTPA were positively associated with $\mathrm{PH}$. The relationship was consistently stronger between LTPA and PH compared to measured MVPA, contrary to our hypothesis. Odds of good PH was over fourfold higher for those in the highest LTPA quartile compared to the lowest, as opposed to MVPA, where the odds of good $\mathrm{PH}$ were modestly higher in the highest quartile, around 1.7-fold, compared to the lowest quartile.

A similar framework was used in an earlier study involving objective and subjective measures of PA and health-related quality of life among middle aged participants [19]. However, the association between accelerometer-measured PA and HRQoL was stronger compared to questionnaire-based measurements of PA; the opposite was observed in our study, where LTPA had a stronger association with $\mathrm{PH}$ than objectively measured MVPA. This discrepancy might be due to different outcome measures (PH vs. HRQoL). Moreover, the possibility that $\mathrm{PH}$ and self-reported PA might have a conceptual overlap could explain the stronger relationship between them in this study. It has been suggested that especially LTPA would have stronger positive association with $\mathrm{PH}$ compared to other PA domains (like household or work related PA) [15, 31, 32]. LTPA is autonomous and often aims for recreation, enjoyment and social interaction and thus has potential to increase mood and psychological health in addition to physiological health benefits [31, 32]. In the study, the agreement between objectively MVPA and self-reported LTPA was low, which indicates that LTPA neglects other domains of PA (e.g. work related, commuting, and 
Table 4 Self-reported leisure time physical activity (LTPA) and accelerometer-measured moderate-to-vigorous activity (MVPA) in relation to $\mathrm{PH}$

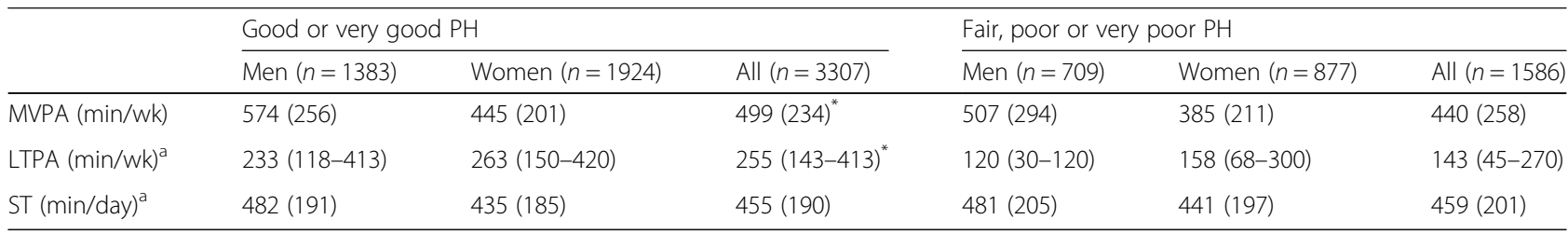

mean (SD) or median (25th-75th percentiles), ${ }^{*}$ different from fair, poor or very poor $(\mathrm{p}<0.001)$, ${ }^{\text {a }}$ self-reported, $\mathrm{PH}=$ perceived health

household activities) which can have moderate or higher intensity and thus are included in the objectively measured MVPA time.

Our findings are in line with an earlier study indicating a positive connection between $\mathrm{PH}$ and objectively measured PA and a lack of connection between PH and ST [16]. Previously, the dose-response relationship between LTPA and PH has also been acknowledged [14]. Other covariates for good $\mathrm{PH}$ found in this study, including higher education, marriage/cohabitation, higher income, and working status have also been widely acknowledged previously (see, e.g., [2, 3, 22]). In this study, gender was not related to $\mathrm{PH}$.

Our results indicate that middle aged participants engaged in an average of $69 \mathrm{~min}$ of MVPA per day (2590 MET-min/wk), as measured with the activity monitor, with men participating in significantly more MVPA than women. In previous studies among middle-aged populations, the amount of accelerometer-measured PA has varied considerably. In the United States, MVPA duration was only 35 and $20 \mathrm{~min} /$ day in men and women respectively [33]. However, a study in Norway reported almost twice as much daily MVPA as the current study, with $117 \mathrm{~min} /$ day [34]. These studies relied on waistworn monitors, and it has been found that wrist-worn monitors provide higher estimates of activity compared to waist-worn monitors due to the wear location [35]. Furthermore, using objective PA measurements may have effected on the PA behavior of the participants during the two-week measurement period in this study.

Self-reported time spent in light and brisk activity during leisure time in this study was around $3 \mathrm{~h} / \mathrm{wk}$., which is less than that reported in previous US study involving the same age group [36]. In this study, women reported significantly more LTPA than men, although based on the objective measurement, men engaged in more MVPA than women. The disparity between measured and self-estimated PA can be explained partly by the questionnaire addressing only the amount and duration of leisure time brisk and light activity. It has been established that 5001000 MET-min/wk. of PA is enough to bring major health benefits [37]. With this criterion, the study population was sufficiently active based on both the questionnaire and the accelerometer.
Time spent sitting was on average $7.5 \mathrm{~h} /$ day based on self-report. Men reported an hour more ST than women per day. Most of the ST was reported to take place at work. Earlier studies involving accelerometer measurements show STs of around the same magnitude in middle-aged people: around $7.5 \mathrm{~h} /$ day in the United States and $8.5 \mathrm{~h} /$ day in Australia [21, 38].

This study has some limitations. Causality between $\mathrm{PA}$ and PH cannot be concluded due to the cross-sectional study design. The lack of accelerometer-measured ST is another limitation, as accelerometer measured and self-reported STs differ. Objective measurement is known to measure a greater amount of ST compared to self-reports [34]. Thus, the actual sitting time in this study might be underestimated. It has been established that measuring ST with wrist-worn monitor has limitations due to its difficulty in posture recognition and with methods used in this study it wasn't possible to differentiate reliably sitting from other low intensity still activities, e.g. standing [39]. The amount of reported sitting time did not differ between good and poor $\mathrm{PH}$, indicating that the amount of sitting is more weakly associated with perception of health compared to PA, which was clearly positively connected with $\mathrm{PH}$.

The methodological limitations of objective and subjective measures of PA when investigating the relationships between $\mathrm{PH}$ and well-being should be acknowledged. While accelerometer measurement is a reliable and continuous measuring method, it does not capture all types of PA precisely, underestimating, for example, cycling and carrying loads. In contrast, PA questionnaires tend to overestimate the true PA level but can provide essential information about the PA type and context [36]. The strengths of the study include a representative population sample and high compliance of activity monitor wear.

\section{Conclusions}

In this population-based study on middle-aged people, the amount of both accelerometer measured moderate to vigorous physical activity and self-reported LTPA were positively associated with $\mathrm{PH}$ regardless of daily time spent sitting. A clear dose-response relationship was 
Table 5 Odds ratios for good perceived health. Model 1 includes accelerometer measured MVPA, Model 2 self-reported LTPA

\begin{tabular}{|c|c|c|c|c|}
\hline Variable & Model 1. N & $\begin{array}{l}\text { OR } \\
(95 \% C l)^{a}\end{array}$ & $\begin{array}{l}\text { Model } \\
\text { 2. N }\end{array}$ & $\begin{array}{l}\text { OR } \\
(95 \% \mathrm{Cl})^{\mathrm{a}}\end{array}$ \\
\hline \multicolumn{5}{|l|}{ Gender } \\
\hline Men & 1931 & 1 & 1892 & 1 \\
\hline Women & 2391 & $\begin{array}{l}1.13 \\
(0.97-1.31)\end{array}$ & 2380 & $\begin{array}{l}0.96 \\
(0.82-1.11)\end{array}$ \\
\hline \multicolumn{5}{|l|}{ Marital status } \\
\hline Married/cohabiting & 3459 & 1 & 3411 & 1 \\
\hline Unmarried & 863 & $\begin{array}{l}0.86 \\
(0.71-1.05)\end{array}$ & 861 & $\begin{array}{l}0.77 \\
(0.63-0.95)\end{array}$ \\
\hline \multicolumn{5}{|l|}{ Education } \\
\hline $\begin{array}{l}\text { Vocational/college } \\
\text { level education or no } \\
\text { vocational education }\end{array}$ & 3021 & 1 & 2987 & 1 \\
\hline $\begin{array}{l}\text { Polytechnic/university } \\
\text { degree }\end{array}$ & 1301 & $\begin{array}{l}1.31 \\
(1.10-1.56)\end{array}$ & 1285 & $\begin{array}{l}1.28 \\
(1.08-1.53)\end{array}$ \\
\hline \multicolumn{5}{|l|}{ Employment status } \\
\hline Working & 3893 & 1 & 3837 & 1 \\
\hline Unemployed & 218 & $\begin{array}{l}0.54 \\
(0.40-0.74)\end{array}$ & 220 & $\begin{array}{l}0.48 \\
(0.35-0.65)\end{array}$ \\
\hline Other & 211 & $\begin{array}{l}0.44 \\
(0.32-0.60)\end{array}$ & 215 & $\begin{array}{l}0.39 \\
(0.28-0.53)\end{array}$ \\
\hline \multicolumn{5}{|l|}{ Smoking } \\
\hline Non-smoker & 2341 & 1 & 2315 & 1 \\
\hline Current smoker & 782 & $\begin{array}{l}0.60 \\
(0.50-0.73)\end{array}$ & 783 & $\begin{array}{l}0.64 \\
(0.53-0.78)\end{array}$ \\
\hline Former smoker & 1199 & $\begin{array}{l}1.00 \\
(0.84-1.18)\end{array}$ & 1174 & $\begin{array}{l}0.97 \\
(0.82-1.15)\end{array}$ \\
\hline \multicolumn{5}{|l|}{$\begin{array}{l}\text { Prevalence of } \\
\text { diseases }^{b}\end{array}$} \\
\hline One or more & 2960 & 1 & 2935 & 1 \\
\hline No & 1362 & $\begin{array}{l}2.16 \\
(1.83-2.55)\end{array}$ & 1337 & $\begin{array}{l}2.27 \\
(1.92-2.69)\end{array}$ \\
\hline
\end{tabular}

Heavy alcohol consumption $^{c}$

\begin{tabular}{|c|c|c|c|c|}
\hline Yes & 353 & 1 & 364 & 1 \\
\hline No & 3969 & $\begin{array}{l}1.43 \\
(1.12-1.83)\end{array}$ & 3908 & $\begin{array}{l}1.31 \\
(1.02-1.69)\end{array}$ \\
\hline $\begin{array}{l}\text { BMI } \\
\text { (continuous, kg/m2) }\end{array}$ & 4322 & $\begin{array}{l}0.90 \\
(0.89-0.91)\end{array}$ & 4272 & $\begin{array}{l}0.90 \\
(0.89-0.92)\end{array}$ \\
\hline \multicolumn{5}{|l|}{$\begin{array}{l}\text { Income quartiles } \\
\text { (k€/year) }\end{array}$} \\
\hline I (0-34.5) & 936 & 1 & 941 & 1 \\
\hline || (34.6-59.5) & 1109 & $\begin{array}{l}1.14 \\
(0.93-1.40)\end{array}$ & 1097 & $\begin{array}{l}1.11 \\
(0.90-1.37)\end{array}$ \\
\hline III (59.6-79.9) & 996 & $\begin{array}{l}1.51 \\
(1.20-1.90)\end{array}$ & 974 & $\begin{array}{l}1.43 \\
(1.13-1.81)\end{array}$ \\
\hline IV $(\geq 80)$ & 1281 & $\begin{array}{l}2.06 \\
(1.62-2.62)\end{array}$ & 1260 & $\begin{array}{l}1.84 \\
(1.44-2.35)\end{array}$ \\
\hline
\end{tabular}

Sitting time quartiles (min/day)
Table 5 Odds ratios for good perceived health. Model 1 includes accelerometer measured MVPA, Model 2 self-reported LTPA (Continued)

\begin{tabular}{|c|c|c|c|c|}
\hline Variable & Model 1. N & $\begin{array}{l}\text { OR } \\
(95 \% C l)^{a}\end{array}$ & $\begin{array}{l}\text { Model } \\
\text { 2. N }\end{array}$ & $\begin{array}{l}\text { OR } \\
(95 \% C l)^{a}\end{array}$ \\
\hline I (20-300) & 982 & 1 & 958 & 1 \\
\hline || (301-480) & 981 & $\begin{array}{l}0.96 \\
(0.78-1.18)\end{array}$ & 968 & $\begin{array}{l}0.97 \\
(0.78-1.20)\end{array}$ \\
\hline III (481-600) & 1154 & $\begin{array}{l}1.04 \\
(0.84-1.23)\end{array}$ & 1160 & $\begin{array}{l}1.06 \\
(0.86-1.31)\end{array}$ \\
\hline IV (601-1080) & 1205 & $\begin{array}{l}0.87 \\
(0.71-1.07)\end{array}$ & 1186 & $\begin{array}{l}0.93 \\
(0.75-1.14)\end{array}$ \\
\hline
\end{tabular}

MVPA quartiles

(min/week)

$\begin{array}{lll}\text { I (7-313) } & 1049 & 1 \\ \text { II (314-440) } & 1068 & \mathbf{1 . 3 7} \\ & & (\mathbf{1 . 1 3 - 1 . 6 7 )} \\ \text { III (441-603) } & 1091 & \mathbf{1 . 4 9} \\ & & (\mathbf{1 . 2 1 - 1 . 8 2 )} \\ \text { IV (604-2638) } & 1114 & \mathbf{1 . 6 6} \\ & & \mathbf{( 1 . 3 5 - 2 . 0 5 )}\end{array}$

LTPA quartiles

(min/week)

$$
\begin{aligned}
& \text { I (0-89) } \\
& \text { || (90-224) }
\end{aligned}
$$$$
914 \quad 1
$$

$$
\text { III (225-374) }
$$$$
1060 \quad 2.41
$$

(1.96-2.96)

IV (375-1260) $1131 \quad 4.33$

$(3.47-5.40)$

MVPA Moderate to Vigorous Physical Activity, LTPA Leisure Time Physical Activity

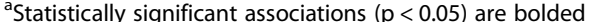

bPrevalence of cardiovascular disease, diabetes mellitus, cancer, musculoskeletal diseases or mental disorder

'Alcohol consumption for men at least $40 \mathrm{~g} /$ day and for women at least $20 \mathrm{~g} /$ day

observed, with both physical activity measures on $\mathrm{PH}$ and higher PA connected to better health. This study encourages use of both objective and subjective measurement of PA and the results can be utilized in policymaking and planning interventions and programs promoting physical activity at population level.

\section{Abbreviations}

BMI: Body mass index; HRQoL: Health related quality of life; LTPA: Leisure time physical activity; MET: Metabolic equivalent of a task; MVPA: Moderate to vigorous physical activity; NFBC66: The Northern Finland Birth cohort 1966 study; OR: Odds ratio; PA: Physical activity; PH: Perceived health; SD: Standard deviation; ST: Sitting time; US: United States

\section{Acknowledgments}

We thank the participants in the 46y study, and the NFBC project center.

\section{Funding}

NFBC1966 received financial support from University of Oulu [grant number 24000692], Oulu University Hospital [grant number 24301140], and ERDF European Regional Development Fund [grant number 539/2010 A31592]. The study has been financially supported by Ministry of Education and 
Culture in Finland [grant numbers OKM/86/626/2014, OKM/43/626/2015, OKM/17/626/2016], and Infotech Oulu, Finland. The funders of the study did not have any role in the design of the study, data collection, analysis, and interpretation or in writing the manuscript.

\section{Availability of data and materials}

The data that support the findings of this study are available from the Northern Finland Birth Cohort (NFBC) for researchers who meet the criteria to for accessing confidential data. Please, contact NFBC project center (NFBCprojectcenter@oulu.fi) and visit the cohort website [23] for more information.

\section{Authors' contributions}

We state following author contributions: literature search: MN, MK, RK, TJ, study design: RK, TJ, TT, SKK, RA, JA, data collection: RA, RK, TJ, AML, SKK, JA, data analysis: MN, RA, MK, AML, EV, RK, TJ, data interpretation: MN, MK, JA, $A M L, T T, E V, S K K, R K, T J$ and writing: MN, MK, RA, JA, AML, TT, SKK, RK, TJ. All authors read and approved the final manuscript.

\section{Ethics approval and consent to participate}

The study was approved by the Ethical Committee of the Northern Ostrobothnia Hospital District in Oulu, Finland (94/2011). Written consent for the study was signed by the subjects and their parents.

\section{Consent for publication}

Not applicable.

\section{Competing interests}

RA is employed by Polar Electro. The company had no role in the conduct of the study or decision to publish. Otherwise the authors declare that they have no competing interests.

\section{Publisher's Note}

Springer Nature remains neutral with regard to jurisdictional claims in published maps and institutional affiliations.

\section{Author details \\ ${ }^{1}$ Research Unit of Medical Imaging, Physics and Technology, University of Oulu, PO Box 5000, 90014 Oulu, Finland. Infotech, University of Oulu, Oulu, Finland. ${ }^{3}$ Medical Research Center, Oulu University Hospital and University of Oulu, Oulu, Finland. ${ }^{4}$ Polar Electro, Kempele, Finland. ${ }^{5}$ Center for Life Course Health Research, University of Oulu, Oulu, Finland. ${ }^{6}$ Department of Sports and Exercise Medicine, Oulu Deaconess Institute, Oulu, Finland. ${ }^{7}$ LIKES Research Centre for Physical Activity and Health, Jyväskylä, Finland. ${ }^{8}$ Health Center of Oulu, Oulu, Finland. ${ }^{9}$ Healthcare and Social Services of Selänne, Pyhäjärvi, Finland. ${ }^{10}$ Diagnostic Radiology, Oulu University Hospital, Oulu, Finland.}

Received: 4 April 2018 Accepted: 21 December 2018

Published online: 07 January 2019

\section{References}

1. Shields M, Shooshtari S. Determinants of self-perceived health. Health Rep. 2001;13(1):35-52.

2. Idler EL, Benyamini Y. Self-rated health and mortality: a review of twentyseven community studies. J Health Soc Behav. 1997;38(1):21-37.

3. Wu S, Wang R, Zhao Y, Ma X, Wu M, Yan X, et al. The relationship between self-rated health and objective health status: a population-based study. BMC Public Health. 2013;13(1):320.

4. Mossey JM, Shapiro E. Self-rated health: a predictor of mortality among the elderly. Am J Public Health. 1982;72(8):800-8

5. Lindström M. Marital status, social capital, material conditions and self-rated health: a population-based study. Health Policy. 2009;93(2):172-9.

6. del Amo González L, MP BV, Martín-Martín J. Long term unemployment, income, poverty, and social public expenditure, and their relationship with self-perceived health in Spain (2007-2011). BMC Public Health. 2018;18(1):133.

7. Krause NM, Jay GM. What do global self-rated health items measure? Med Care. 1994;32(9):930-42.

8. Maddox GL, Douglass EB. Self-assessment of health: a longitudinal study of elderly subjects. J Health Soc Behav. 1973;14(1):87-93.
9. Wen CP, Wai JP, Tsai MK, Yang YC, Cheng TY, Lee MC, et al. Minimum amount of physical activity for reduced mortality and extended life expectancy: a prospective cohort study. Lancet. 2011;379:1244-53.

10. Lee IM, Shiroma E, Lobelo F, Puska P, Blair S, Katzmarzyk P. Effect of physical inactivity on major non-communicable diseases worldwide: an analysis of burden of disease and life expectancy. Lancet. 2012;380:219.

11. Ding D, Lawson KD, Kolbe-Alexander TL, Finkelstein EA, Katzmarzyk PT, van Mechelen W, et al. The economic burden of physical inactivity: a global analysis of major non-communicable diseases. Lancet. 2016; 388(10051):1311-24.

12. Strath SJ, Kaminsky LA, Ainsworth BE, Ekelund U, Freedson PS, Gary RA, et al Guide to the assessment of physical activity: clinical and research applications. Circulation. 2013;128(20):2259-79.

13. Ainsworth BE, Levy SS. Assessment of health-enhancing physical activity. Methodological issues. In: Oja P, Borms J, editors. Health enhancing physical activity. Oxford: Meyer \& Meyer Sport; 2004. p. 239.

14. Galán I, Meseguer CM, Herruzo R, Rodríguez-Artalejo F. Self-rated health according to amount, intensity and duration of leisure time physical activity. Prev Med. 2010;51(5):378-83.

15. Abu-Omar K, Rütten A. Relation of leisure time, occupational, domestic, and commuting physical activity to health indicators in Europe. Prev Med. 2008; 47(3):319-23.

16. Hamer M, Stamatakis E. Objectively assessed physical activity, fitness and subjective wellbeing. Ment Health Phys Act. 2010;3(2):67-71.

17. Husu P, Vähä-Ypyä H, Vasankari T. Objectively measured sedentary behavior and physical activity of Finnish 7- to 14-year-old children- associations with perceived health status: a cross-sectional study. BMC Public Health. 2016;16:338.

18. Malmberg J, Miilunpalo S, Pasanen M, Vuori I, Oja P. Characteristics of leisure time physical activity associated with risk of decline in perceived health-a 10-year follow-up of middle-aged and elderly men and women. Prev Med. 2005:41(1):141-50

19. Anokye N, Trueman P, Green C, Pavey T, Taylor R. Physical activity and health related quality of life. BMC Public Health. 2012;12:624.

20. Borodulin K, Mäkinen TE, Leino-Arjas P, Tammelin TH, Heliövaara M, Martelin T, et al. Leisure time physical activity in a 22-year follow-up among Finnish adults. IJBNPA. 2012;9(1):1-6.

21. Matthews CE, Chen KY, Freedson PS, Buchowski MS, Beech BM, Pate RR, et al. Amount of time spent in sedentary behaviors in the United States, 20032004. Am J Epidemiol. 2008 April 01;167(7):875-81.

22. Põld M, Pärna K, Ringmets I. Trends in self-rated health and association with socioeconomic position in Estonia: data from cross-sectional studies in 1996-2014. Int J Equity Health. 2016;15:200.

23. Northern Finland Cohorts. Available at: http://www.oulu.fi/nfbc/. Accessed 10 Jan 2018.

24. Tammelin T. Physical activity from adolescence to adulthood and healthrelated fitness at age 31 . Cross-sectional and longitudinal analyses of the northern Finland birth cohort of 1966. Oulu: University of Oulu; 2003.

25. Suija K, Timonen M, Suviola M, Jokelainen J, Järvelin M, Tammelin T. The association between physical fitness and depressive symptoms among young adults: results of the northern Finland 1966 birth cohort study. BMC Public Health. 2013;13(1):535.

26. Peltonen M, Harald K, Männistö S, Saarikoski L, Lund L, Sundvall J, et al. National FINRISK 2007 study. Study implementation and results: table supplement(In Finnish). Publ Natl Public Health Inst. 2008;B35:338.

27. Hautala A, Martinmaki K, Kiviniemi A, Kinnunen H, Virtanen P, Jaatinen J, et al. Effects of habitual physical activity on response to endurance training. J Sports Sci. 2012;30(6):563-9.

28. Kinnunen $\mathrm{H}$, Tanskanen M, Kyröläinen H, Westerterp KR. Wrist-worn accelerometers in assessment of energy expenditure during intensive training. Physiol Meas. 2012;33(11):1841-54.

29. Jauho A, Pyky R, Ahola R, Kangas M, Virtanen P, Korpelainen R, et al. Effect of wrist-worn activity monitor feedback on physical activity behavior: a randomized controlled trial in Finnish young men. Prev Med Rep. 2015;2:628-34.

30. Husu P, Suni J, Vähä-Ypyä $H$, Sievänen $H$, Tokola $K$, Valkeinen $H$, et al. The level of physical activity and sedentary behaviour in Finnish adults. Suomen Lääkärilehti. 2014;25-32:1860-6.

31. Lera-López F, Ollo-López A, Sánchez-Santos JM. How does physical activity make you feel better? The mediational role of perceived health. Appl Res in Quality of Life. 2017;12(3):511-31. 
32. Bogaert I, De Martelaer K, Deforche B, Clarys P, Zinzen E. Associations between different types of physical activity and teachers' perceived mental, physical, and work-related health. BMC Public Health. 2014;14:534.

33. Troiano RP, Berrigan D, Dodd KW, Masse LC, Tilert T, McDowell M. Physical activity in the United States measured by accelerometer. Med Sci Sports Exerc. 2008:40(1):181.

34. Dyrstad SM, Hansen BH, Holme IM, Anderssen SA. Comparison of self-reported versus accelerometer-measured physical activity. Med Sci Sports Exerc. 2014; 46(1):99-106.

35. Leinonen A, Ahola R, Kulmala J, Hakonen H, Vähä-Ypyä H, Herzig K, et al. Measuring physical activity in free-living conditions-comparison of three Accelerometry-based methods. Front Physiol. 2017;7:681.

36. Tucker JM, Welk GJ, Beyler NK. Physical activity in U.S. adults: compliance with the physical activity guidelines for Americans. Am J Prev Med. 2011; 40(4):454-61.

37. U.S. Department of Health and Human Services. Physical Activity Guidelines for Americans. 2008.

38. Healy GN, Dunstan DW, Salmon J, Cerin E, Shaw JE, Zimmet PZ, et al. Objectively measured light-intensity physical activity is independently associated with 2-h plasma glucose. Diabetes Care. 2007;30(6):1384-9.

39. Byrom B, Stratton G, Mc Carthy M, Muehlhausen W. Objective measurement of sedentary behaviour using accelerometers. Int J Obes. 2016;40(11):1809-12.

Ready to submit your research? Choose BMC and benefit from:

- fast, convenient online submission

- thorough peer review by experienced researchers in your field

- rapid publication on acceptance

- support for research data, including large and complex data types

- gold Open Access which fosters wider collaboration and increased citations

- maximum visibility for your research: over $100 \mathrm{M}$ website views per year

At BMC, research is always in progress.

Learn more biomedcentral.com/submissions 